inferior professional experience to challenge the correctness of his deductions or place his own "guessings" and "imaginings" cûté-à-côté with Sir J. Paget's. Nevertheless, while it is given to few, I should imagine, to search the records of prehistoric times for those types of disease maintained with such tenacity that they are recognised by physicians and pathologists as existing at the present time, it mav still be a moot point, and one capable of being argued, whether the so-called deviations or new diseases may not be accounted for on some other ground than that of having only escaped $a b$ ovo in the present century. However, without discussing the new disease theory, it is not a little remarkable that when attention bas once been drawn to some phase of morbid action furmerly of rare occurrence, perhaps scarcely noticed, numerous examples appear to spring up suddenly, and become the subject of general observation. This, I think, is particularly noticeable in diseases of the beart and bloodvessels. Amongst, these, heart-clot and embolism are notable instances. Thus, in one number of THe LANCET, in January, we find three rather long articles on embolism, a condition which Sir J. Paget has expressly pronounced not to be a new disease. About the same time I was called to a case which, as it is connected with this subject and presents some unusual festures, I beg permission to relate.

The patient was supposed to be suffering from apoplexy. The young woman in charge of the house where the patient lived was of an observant nature, and, as she stated, not at all nervous. She had heard that stertorous breathing indicated apoplexy. The patient, after sine became insensible, had stertorous breatbing, the ergo was therefore clear enough. Before I reached the house I was met by the messenger, who anxiously inquired whether it was not a bad symptom if on touching the eye the lids did not close. I was therefore fully prepared to see death. On the bed lay a young woman who, I was told, was sixteen years of age, but presented the appearance of nineteen. The young woman in charge, the eye-tester, gave the following account:- The night previous to the patient's death she was attacked with severe headache and sickness, the vomited matter having the appearance of bile, and to this cause the illness was attributed. The next day she got up, but was not allowed to work. She made very little complaint during the day. Although sickness had not returned she was disinclined to take food, which seemed further to confirm the notion of its being a bilious attack. Between 5 and 6 o'clock she became worse, was assisted mpstairs, undressed, and put to bed, complaining greatly of her head. A bout 9 o'clock convulsive strugglings came on, the fdce and lips assuming a dark hue. It then appeared to the person in charge time to send for a medical man. I receired the message at 9.30 P.M. and at 9.40 , when I arived at the house, the patient was dead. I think the natural surmise would he that some cerebral mischief was the cause of death. The post-mortem revealed no such indication. No ruptured vessel, clot, or effusion of any kind the brain substance was of natural firmness; the puncta not unusually numerous. The lungs were much congested with many tubercular deposits in the cretaceous state. The liver was also congested, but no particular collection of bile in the gall-bladder. The stomach contained a little fluid, but there were no patches of discolouration. In the pericardium there was a little effusion of sanguineous hue. The walls of the heart prezented a mottled appearance from fatty degeneration; the right ventricle was filled with coagulum, which escaped as the cavity was opened, amongst which was clot of firm fibrine, about the size and shape of a pigeon' egg, weighing nearly half an ounce. On inquiry, the family history revealed phthisis and heart disease. The deceased's mother died from heart disease; her aunt was found dead in bed, and was known to suffer from heart disease; other members also suffered from the same and from phtbisis.

I thiuk the case presents several points of interest. Upon a cursoly examination the symptoms seemed to indicate stomach derangement affecting the head, or head trouble cansing the stomach disturbance. No complaint of pain in the region of the heart; no shortness of breath, except on one 0?csion after stooping, which attracted no particular attention then, but was remembered by a fellow-servant; no previous illness of any kind, having had good health from childhood. Then the early period for such a formation, the $\checkmark 2$ of the clot, and the absence of any indication of the jre:ecce of such a substance in the heart, where one would think a body of that size would be driven against aud seriously interf $f_{\text {re }}$ with the action of the valves. Then how can we account for its formation and growth? There is no account of cardiac trouble, phlebitis, rheumatism, or inflammatory attack of any kind ; indeed, no disease either new or old on which to base a theory. Must we fall back on "inherited disease," which implies so much, yet reveals so little, of the how and why of morbid action and pathological changes? Constitutional diathesis might answer, combining inherited proclivities and individual peculiarity. I suppose, looking at the fact that several members of the family suffered from disease of this organ, and, as Sir J. Paget says (speaking of phlebitis), it is not accident which determines the disease to the veins, for it runs in families; and, as in osteitis deformans, "a likeness may be imagined to several other diseases which may indicate a combination in definite proportions of transmitted disposition to those diseases," or by "further imagining" and "guessing to the furthest bounds of propriety"; and thus by exercising the use of the imagination, "which may happily discover a way towards the truth,"-we may arrive at the conclusion that "combinations in definite proportions accumulating and converging," formed this egg shaped half ounce of fibrine in the heart. I am, Sir, yours faithfully,

St. Mark's-square, E., Sept. 1883

Charles Day.

\section{"LOOSE CARTILAGE IN THE KNEE-JOINT."} To the Editor of THE LANCET.

SIR,-Having read in your last issue an account of a loose cartilage removed from the knee-joint of a student at King's College Hospital by Mr. Royes Bell, it may interest your readers to read an account of another similar case.

I may state that I am an old student of King's College, and that a loose cartilage was removed from my right knee-joint in April last. As far as I can remember I eprained my knee at cricket, and it gave me some pain at the time, but I was not confined to bed or the house at any time. A Jear or two afterwards I often felt a sudden pain on the inner side of the joint, and would be lame for some time; then all pain would suddenly cease, and I would not feel it again for weeks. A bout this time $I$ felt what appeared to be a foreign body under the skin, about the size of a split pea, and this went on for about two years more. I never detected any swelling or excess of synovia in the joint. I should state, however, that I have suffered for years from rheumatism of the joints-knee, hip, and shoulder; but never from an acute attack.

In April of this year. after extra exertion at lawn tennis, I suddenly, and for the first time, felt excessive pain on the outside of the right knee-joint. On examination, a small body. similar in size to what I had before felt on the inner side, could be detected under the skin. The pain was more acute thau anything $\mathrm{I}$ had experienced before, and prevented we from extending the leg. I was unable, too, to push the small body back in to the joint. I therefore fixed it with plaster and a light bandage, and asked my old friend, Dr. T. D. Griffiths of Swansea, to examine and remove it. On the following day he cut down upon it antiseptically, and removed it. Had I known it would have been such a painful and tedious operation, for it slipped into the joint once or twice, and was with considerable difficulty seized, I would certainly have taken chloroform or ether. Three sutures were inserted, the wound was dressed, and a back splint applied. Two days after it was again dressed, when not a particle of pus escaped, and practically the wound was healed-no swelling; no pain now present. A plaster-of-Paris bandage was plactd round the joint, and seven days after everything was taken off, and I was able to walk about, and felt only a little stiffness. From that time to this I have been absolutely free from pain in the joint; but I regret to say I have had considerable and persistent pain in the back of the left knee-joint, evidently showing that rheumatiom is still lurking iu wy system, and seems to defy all treatment.

I ought to state that when removed it was the siza of a split pea, white and glistening; oval on one side, convex on the other.

Morriston, Sept. 17th, 1883.

E. Rice Morgan.

THE prevalence of scarlet fever in Dudley has made it expedient, in the view of the School B oard, to close for the present all the schools under their jurisdiction in the town. 